\title{
Financial Analysis: Current Situation and Development Trend-Review and Evaluation of Corporate Financial Analysis
}

\author{
Jinyu Tian ${ }^{1, a}$, Sijia He $\mathrm{H}^{1, \mathrm{~b}}$ \\ ${ }^{1}$ School of North China Electric Power University, Baoding 071000, China; \\ a434668545@qq.com, b604526880@qq.com,
}

Keywords: financial analysis; methods of financial analysis; problems and limitations; development trend.

\begin{abstract}
In financial analysis, the users of financial information refer to corporate financial statements and other relevant information to assist subject of financial analysis to make scientific decision via scientific analysis system, evaluation of past and present and reasonable prediction to the future. Firstly, concept, history origin and development status of financial analysis are described. Then methods of currently financial analysis are respectively introduced and their problems and limitations are summarized. Finally, development trend of financial analysis is forecasted.
\end{abstract}

\section{Concept and Development of Financial Analysis}

\subsection{Concept of financial analysis}

In financial analysis, the users of financial information refer to corporate financial statements and other relevant information to assist subject of financial analysis to make scientific decision via scientific analysis system, evaluation of past and present and reasonable prediction to the future. According to the definition of financial analysis, financial analysis features can be elaborated from the following five aspects.

(1) Subjects of financial analysis. With the development of economic and improvement of laws and regulations, range of enterprise stakeholders is growing, users of financial information. Users of financial information are not just limited to the investors, creditors and managers and also include the employees, customers, government, potential investment and other related interests.

(2) Objects of financial analysis. In order to carry out financial analysis more scientific and reasonable in financial analysis, not only main data including financial statements and other financial information are required to be quantitatively analyzed, important non-financial information other than financial statements are also needed to be qualitatively analyzed

(3) Methods of financial analysis, which can be classified into quantitative analysis and qualitative analysis method. Basically, there have methods of comparative analysis, trend analysis, ratio analysis, factor analysis and comprehensive analysis. Due to the complexity and integrity of enterprise's economic activities and financial activities, multiple analytical methods will be combined for analysis in financial analysis

(4) Objective of financial analysis. Although different subjects of financial analysis have different financial analysis objectives, those objectives can be summarized to make scientific decisions based on analysis of past information, evaluation of current state of rationality and prediction of future trends.

(5) The nature of financial analysis. Financial analysis originally derived from the practice of financial analysis. With the expanding of financial analysis range and the continuously improvement of requirements by information users, ways and means of financial analysis are also increasingly scientific and perfect. Financial analysis has become an independent discipline.

\subsection{Origin and Development of Financial Analysis}

Financial analysis originated in the early 19th century in United States. It is the product of the industrial development. Financial analysis is initially applied in the banking sector for bank analysis of debt paying ability of loan enterprises ${ }^{[1]}$. Later, financial analysis is extended from bank loans services to investors' services. Investors mainly make investment decisions through analysis of enterprise solvency and profitability ${ }^{[2]}$. Then, with the further development of corporate organizations, company manager is aware of the importance of financial analysis. 
With the complicated business activities, people gradually found that the single financial index reveals only one aspect of enterprise information and can not fully evaluate the whole enterprise's financial condition and operating results. So the financial analysis began to develop upon comprehensive index system ${ }^{[3]}$.

American DuPont invented the DuPont analysis system in 1910. According to quantitative relationship between the basic financial ratio indexes, comprehensive financial analysis model is established $^{[4]}$. Then from the ultimate goal to enterprise required by investors and layers of index decomposition, various factors influencing ultimate achievement of financial goals is systematic analyzed. In 1919, Alexander Wall from American proposed ratio analysis system, providing a complete guide system of financial analysis for external enterprise.

After Second World War, with the rapid development of science and technology and the increasingly fierce market competition, various measurement methods and models are gradually applied to financial analysis for better development of enterprise.

In 1960s, with the increasing investment risk, a currency time value based investment analysis system is established, mainly including net present value method, internal rate of return method and profit index method ${ }^{[5]}$. At the same time, operating leverage, financial leverage analysis and portfolio analysis methods have also been developed. In 1990s, the study of Robert Kaplan and David Norton helped Balanced Scorecard theory to be systematized. In 1991, Stern Stuart consulting company from United States created a new enterprise performance measurement index -- economic value added(EVA).

EVA refers to the difference between net operating profit and capital (equity capital and debt capital) opportunity cost. Its core idea is as follows: enterprise revenue can create value for the enterprise and create wealth for shareholders only after cost of operating expense and cost of invested capital are both fully compensated. EVA, these methods can make comprehensive financial analysis and more comprehensive and reasonable evaluation to financial situation of enterprise, which is more helpful for financial analysis personnel and enterprise managers to master enterprise's financial position and operating condition ${ }^{[6]}$.

\section{Methods of Financial Analysis}

\subsection{Single financial analysis method}

(1)Ratio Analysis method

In financial ratio analysis, relevant data between several important projects in same period financial statements are compared. Then calculate the ratio with a data divided by another data. Finally compare ratio with standard value, industry value, plan value and historical value, according to which we analyze and evaluate business performance and financial situation. This is the basic method of financial analysis

Financial ratios include solvency, operating capacity ratio, profitability ratio and development capacity ratio. Ratio analysis method is widely used in financial analysis ${ }^{[7]}$. However there also have some limitations as follows: ratio analysis belongs to static analysis, which is difficult to reflect dynamic situation; ratio analysis uses historical data to predict future, which is not entirely reasonable and reliable; Date used in ratio analysis is book cost, which can not reflect the influence of price change. Therefore, in the use of ratio analysis, various ratios should be organically linked up to conduct a comprehensive analysis. Meanwhile, it should be combined with comparative analysis and factor analysis to make a more comprehensive analysis for corporate history, current situation and the future.

(2)Comparative analysis

In comparative analysis, current financial condition of company is compared with previous financial situation in different periods to reveal change trend of company's financial situation or company's financial situation is compared with industry average or other companies to understand the level of company in same industry and existing problem in financial situation. The former one is longitudinal comparison and the latter one is horizontal comparison. 


\section{(3)Factor Analysis}

Factor analysis method, based on relationship between analysis of indicators and influence factors, determines influencing degree brought by various factors changes to index in quantity. Determination of the degree of influence of each factor from the quantity can help people seize the main contradiction or evaluate operating conditions more convincingly. Interlocking substitution is the most commonly used method in factor analysis. In this method, if there are a number of factors influence the analyzed object, people assume other factors remain unchanged and then orderly determine the impact of every single changing factor.

\subsection{Comprehensive financial analysis}

Comprehensive analysis method refers to the comprehensive analysis of relationship between various financial indicators in order to fully understand financial situation of enterprises.

(1)DuPont analysis system

DuPont analysis system uses the internal relations between main financial ratio indicators to comprehensively analyze and evaluate financial situation and economic benefits of enterprises. The system takes return on equity as leader and takes return on assets and equity multiplier as core focus, which reveals the effect return on equity brought by corporate profitability and equity multiplier and also reveals the interaction between relevant indicators. Firstly, it reflects production and business profitability of enterprise and assets management profitability. Secondly, it reflects The costs of enterprises. Thirdly, it reflects the structure of the enterprise current assets and non-current assets.

(2)Balanced Scorecard

Careersmart Balanced Score Card derived from future organizational performance measure engage by Harvard University professor Robert Kaplan and Nolan Norton Institute CEO David Norton in 1990s. Purpose of that program is to jump out traditional financial performance evaluation model to seek a more comprehensive method considering the every aspects of enterprise. The balanced scorecard method breaks traditional performance management which only focus on financial indicator. In industrial age, management methods focusing on financial Index management are still valid. However, in current information society, traditional performance management method is not comprehensive and organizations must invest in customers, suppliers, employees, organizational processes, technology and innovation to obtain sustainable development. Based on this acknowledgement, in balanced score card method, organization should examine its performance in four perspectives: learning and growth, business process, customer and financial.

(3)The Wall rating method

In $<$ Credit Barometer Study $>$ and $<$ Ratio analysis of financial statements $>$ Alexander Wall proposed the concept of "credit capacity index", which becomes embryonic form of "The Wall rating method". The basic procedure is as follows: first, choose certain financial ratios and endow then with a certain score or weight. Then determine each the ratio of standard value and calculate the score of every ratio by multiplying the relative value (obtained by dividing actual value with standard value of the ratio) with weights. Finally, add all the scores to get the total score. According to difference life cycles and development strategies of enterprise, weights of various financial ratios are respectively set to evaluate enterprise's financial condition and performance more objectively and comprehensively.

\section{Limitations of Financial Analysis}

Limitations and hysteresis of financial statements. Financial statements are basis for financial analysis; the limitations of financial statements will become the limitation of financial analysis. In essence, financial analysis is to compare the calculated index according to financial statements. However, different enterprises' scales, calculation methods and enterprises' life cycles will inevitably lead to different impact on results of the financial analysis ${ }^{[8]}$. Therefore, analysis results with historical data are certainly unsatisfactory and may even lead to opposite conclusion.

Imperfections of financial analysis content. Many factors are not reflected in financial statements and existing methods of financial analysis can not reveal these factors. Development of an enterprise will be subject to political, economic, society and many other factors. These factors, such as 
industry cyclical factors, technological innovation factors, human resources factors and so on, cannot be reflected from financial ratios and financial statements,

Limitations of financial analysis. Due to limitations of the financial analysis, some factors cannot be quantified, which makes financial analysis method imperfect. An enterprise's financial situation and operating results are not only affected by some financial figures, but also influenced by other factors as enterprise business strategy, product life cycle, cooperative spirit of employees and leader's personal quality. Discussion from digital to digital, financial analysis into digital and table stack, all these analyses is difficult to reveal enterprises operating conditions and to find out the problems existing in enterprise operation. Thus, it is difficult to guide business decision policy.

\section{Trends of Financial Analysis}

\subsection{More extensive basis for financial analysis}

Analysis of outside sheet information. The fixed format and the characteristics of main feature reflected by figures $\backslash$ of accounting statements decide its limitations of financial information. On one hand, with the development of social economy and the increasing uncertainty, some information of reports becomes blurred. On the other hand, much important information cannot be accommodated in reports. The various forms of information outside reports, not sticking to formalities, can compensate for the deficiencies in table. At present, a development trend of international financial reporting system is that there are more and more general information in the table, table information is increasingly rich and quality of information is higher. Obviously, analysis only limited to table information is not enough. Information analysis outside table becomes more and more important.

Analysis of segment information. In recent years, mergers and acquisitions are popular. Cross-industry and cross-border group of companies increasingly emerge. Technology, capital and profitability of each branch, investment risk and development prospect in various branches are different. Consolidated financial statements in parent company are too general, which makes it difficult to analyze company's true financial condition and operating results. Therefore, analysis of segment information is often more effective compared with analysis of consolidated statements. Based on analysis of segment information, firstly, people can better understand the company's operating performance in the past; secondly, people can evaluate company's gains and risks more comprehensively; thirdly, future profitability and development prospects can be forecasted more accurately, which will help to make more rational judgment on company.

\subsection{The main purpose of financial analysis is prediction}

At present, relevance between historical information of financial report and economic decisions of users is increasingly decreasing. Since decision is future oriented, user try to grasp financial information in order to make a benefit for future financing, investment and operation decision. Hence, information prediction of enterprises future development is more practical and valuable than historical information. Forecast and analysis are especially important. In order to make an accurate financial forecast and analysis, in analysis of current financial report, it is important to revise historical information in financial report according to the change of subjective and objective conditions.

\subsection{Concise and applicable financial analysis}

Results of the financial analysis are submitted to relevant financial information users in the form of financial analysis report. Its applicability features must be highlighted in order to strengthen transfer function of financial information in financial analysis report. Since there have lots of financial information, financial analysis report cannot be exhaustive. Thus, contents of report should be varied accordingly. Reports send to senior management of company should provide macro information relevant with company development strategy ${ }^{[9]}$. Reports send to middle managers of company should provide microscopic information relevant with company business decisions. Finally, expertise level of reports readers should be familiar. Analysis reports send to financial professionals can detail principles and processes of financial analysis and professionally explain every financial indicator. But reports send to non-financial professionals should omit complicated mathematical model analysis and avoid using terminology to make reports easier to understand. 


\section{References}

[1] William C. Norby(2013). Accounting for financial Analysis [J]. Financial Analysis Journal 2013(7-8):18-19, 77-80

[2] Arthur L. Thomas, the Allocation Fallacy and Financial Analysis, Financial Analysts Journal, September-October 2014, 37-41

[3] Ball R. P. Brown. An Empirical Evaluation of Accounting Income Numbers. Journal of Accounting Research. Autunm2015:159-178.

[4] Fama E. F. ,Efficient Capital Markets: A Review of Theory and Empirical Work. Journal of Finance. May2013383-417.

[5] Ball R. P. Brown. An Empirical Evaluation of Accounting Income Numbers. Journal of Accounting Research. Autunm2014:159-178.

[6] IECAW.2014.The future shape of financial reports.

[7] George H. Sorter, an "Events” Approach to Basic Accounting Theory, The accounting review, 2012(1):12-19

[8] Improving business reporting- a customer focus; meeting the information needs of investors and creditors (AICPA, 2014)

[9] Michael H. Sutton. Financial Reporting at a Crossroads[J].Accounting Horizons, Vol.16. No.4, 2012 (12): 319-328 